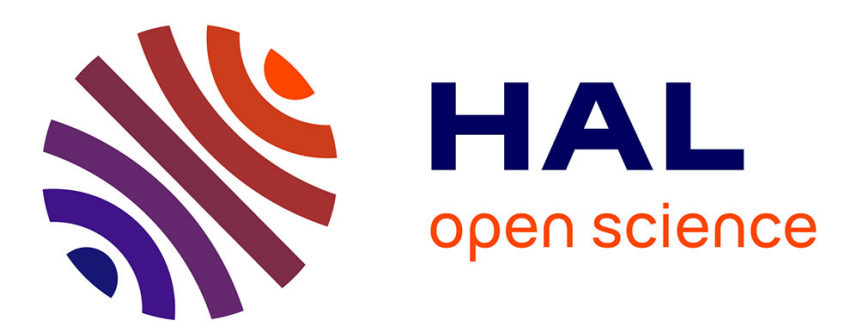

\title{
Filtering Performances of 20 Protective Fabrics against Solid Aerosols
}

\author{
Loïc Wingert, Yves Cloutier, Stéphane Halle, Ali Bahloul, Dominic Tessier, \\ Jean-Luc Giraudel, Patricia Dolez, Ludovic Tuduri
}

\section{- To cite this version:}

Loïc Wingert, Yves Cloutier, Stéphane Halle, Ali Bahloul, Dominic Tessier, et al.. Filtering Performances of 20 Protective Fabrics against Solid Aerosols. Journal of Occupational and Environmental Hygiene, 2019, 10.1080/15459624.2019.1628967 . hal-02179261

\section{HAL Id: hal-02179261 https://hal.science/hal-02179261}

Submitted on 10 Jul 2019

HAL is a multi-disciplinary open access archive for the deposit and dissemination of scientific research documents, whether they are published or not. The documents may come from teaching and research institutions in France or abroad, or from public or private research centers.
L'archive ouverte pluridisciplinaire HAL, est destinée au dépôt et à la diffusion de documents scientifiques de niveau recherche, publiés ou non, émanant des établissements d'enseignement et de recherche français ou étrangers, des laboratoires publics ou privés. 
Filtering Performances of 20 Protective Fabrics against Solid Aerosols

Loïc Wingert $^{\mathrm{a}, \mathrm{b}}$, Yves Cloutier ${ }^{\mathrm{a}}$, Stéphane Hallé ${ }^{\mathrm{b}}$, Ali Bahloul ${ }^{\mathrm{a}}$, Dominic Tessier $^{\mathrm{c}}$, JeanLuc Giraudel $^{\mathrm{d}}$, Patricia Dolez ${ }^{\mathrm{e}}$, Ludovic Tuduri ${ }^{\mathrm{a}}$

${ }^{a}$ Institut de recherche Robert-Sauvé en Santé et en Sécurité du Travail, PRCB, Montreal, Qc, Canada

${ }^{\mathrm{b}}$ École de Technologie Supérieure, Department of Mechanical Engineering, Montreal, Qc, Canada

${ }^{\mathrm{c}}$ Groupe CTT, St-Hyacinthe, Qc, Canada

d UMR 5805 EPOC, Équipe de recherche LPTC, Université de Bordeaux, 33405 Talence, France

${ }^{\mathrm{e}}$ Department of Human Ecology, University of Alberta, Edmonton, AB, Canada

KEYWORDS: Chemical protective clothing, Non-woven, Aerosols, Filtration 


\section{ABSTRACT}

Workers can be exposed to solid airborne particles in some occupational environments and they might be required to wear chemical protective clothing to prevent skin exposure. Dedicated standards exist to certify the protective value of such clothing, but they are not informative enough to identify the main pathways on entries for solid particles, and to compare performances between different chemical protective clothing. In this work, twenty non-woven fabrics used for manufacturing chemical protective clothing against solid particles were selected to study their filtration and comfort performances. Nine were microporous fabrics (MP), ten were multilayered nonwoven fibrous media (SMS) and one was a flash spun material (FS). To assess their filtration performances, they were challenged in a benchtop wind tunnel with a 20 to $3000 \mathrm{~nm}$ diameter sodium chloride aerosol at three low fabric face velocities $(0.05,0.15,0.3 \mathrm{~cm} / \mathrm{s})$. Measurements of airflow resistance and water vapor transmission rate were also performed to provide indications of comfort for the wearer. The penetration results led to the classification of the 20 fabrics into distinct groups of filtration efficiency. The data were analysed based on the porous media characteristics (thickness, fiber diameter, porosity, etc.). MPs were the most efficient fabrics and SMSs showed a wide range of performances, mostly due to variations in the thickness of the filtering layer as well as to the fabrics' treatment. The airflow resistance and water vapor transmission rate results revealed major differences between MPs and FSs on one hand, and SMSs on the other hand. This highlights the potential of some SMS fabrics to meet a compromise between protection and comfort. 


\section{INTRODUCTION}

Workers are occupationally exposed to chemical and physical agents through inhalation and skin contact. Contrary to exposure via inhalation, no occupational exposure limits (OEL) were defined for dermal exposure. ${ }^{[1]}$ At the moment, some chemicals are given "Skin Notations (SK)" ${ }^{\text {[2] }}$ based on a hazard assessment which can vary from country to country. ${ }^{[3]}$ The National Institute for Occupational Health and Safety (NIOSH) has recently reviewed its strategy to assign SKs to chemicals and better communicate the hazards of chemical exposure to the skin. ${ }^{[2]}$

With or without SKs, some chemicals present as aerosols in workplaces can be harmful and cause airborne contact dermatitis for instance. ${ }^{[4]}$ This is the case for aerosols made of metals ${ }^{[5-6]}$ (beryllium, nickel, silver, mercury, gold) or glass fibers. ${ }^{[4-5]}$ Beside the nature of the aerosols, their size can also be a major factor to consider when risk assessment is done. Although scarce in number, existing studies warn about nanoparticle toxicity. ${ }^{[7-10]}$ It has also been shown that nanoparticles could be absorbed by the skin. ${ }^{[7]}$

To prevent skin exposure to these particles some chemical protective clothing might be recommended for workers. According to ISO $16602,{ }^{[11]}$ those chemical protective clothing designed to protect against solid aerosols are referred to as "Type-5" and must comply with the performance requirements described in the ISO standard 13982-1. ${ }^{[12]}$ Chemical protection is evaluated by measuring the total particle inward leakage. This consists in measuring mass-based particle concentration inside and outside a protective clothing worn by a subject performing exercises in an environmental chamber. ${ }^{[13]}$

Although such an approach is relevant for standardization, it lacks the 
consideration of important factors that could inform on the particle penetration pathways (seams, zipper, material, skin/clothing interface). Also, as there are no classes of performance for this type of protective clothing, it is impossible to compare between different Type-5 protective clothing based on the chemical protection they provide to the wearer. Finally, these standards do not require any physiological measurement of the wearer, making it difficult to choose a specific Type-5 protective clothing based on both comfort and protection.

Few studies have been conducted to improve our understanding of the determinants of the protection levels provided by particle-proof protective clothing, Type- 5 certified or not. These studies first investigated fabrics by performing filtration experiments, where aerosol particles were pulled through a clothing sample while monitoring the particle concentration upstream and downstream. ${ }^{[14-15]}$ A limited number of non-woven and woven fabrics were tested (hairnets, cleaning cloths, lab coats, protective clothing). ${ }^{[16-17]}$ The fabric face velocities in such experiments ranged from 0.25 $\mathrm{cm} / \mathrm{s}$ to $0.6 \mathrm{~cm} / \mathrm{s} .{ }^{[14-16]}$ It especially appeared that cotton woven fabrics are not suitable to avoid nanoparticle penetration and that non-woven materials should be preferred. Some filtration experiments performed on seams and zippers ${ }^{[15]}$ highlighted the importance of these points of entry for nanoparticles.

Assuming that the filtration approach was not simulating the field use of protective clothing, some authors ${ }^{[16,18]}$ developed an experimental setup to study penetration of particles when no air was pulled through the fabric, called the "diffusion through" method. Although limited to three protective clothing fabrics (one from a Type5 certified clothing), these studies highlighted a possible penetration of nanoparticles 
under pure diffusional conditions. Some other authors ${ }^{[17]}$ developed a closed-loop wind tunnel to measure the penetration of submicron particles at different wind speeds. While this setup could mimic real workplace exposure (one wind speed in the tunnel associated with different natural infiltration flow rates depending on the type of fabric), the authors adjusted the wind speed to reach the same fabric face velocities for all fabric samples $(0.009 \mathrm{~cm} / \mathrm{s}, 0.018 \mathrm{~cm} / \mathrm{s}$ and $0.027 \mathrm{~cm} / \mathrm{s})$. Thus, the implementation of this method equalled a classical filtration approach at low fabric face velocities.

This literature review highlights the fact that the ISO standardized test for Type-5 protective clothing does not provide enough knowledge that could allow workers finding the right balance between comfort and the protection they need. It also shows the paucity of data in the literature regarding the performance of Type- 5 protective clothing fabrics. Finally, it is worth pointing out that all the previously cited studies dealt with particles smaller than $500 \mathrm{~nm}$ (nanoparticles and sub-micron particles), while the Type-5 certification assesses the clothing performances using an aerosol with a broad particle size distribution, from $20 \mathrm{~nm}$ to $2000 \mathrm{~nm}$. Therefore, this project aimed at studying and explaining the performances of a large panel (20) of protective fabrics against solid aerosols. To do so, the fabric protection performances were evaluated for a broader particle size range ( $20 \mathrm{~nm}$ to $3000 \mathrm{~nm}$ ). In addition, three very low superficial velocities were used to simulate as closely as possible real work conditions. Measurements of fabric thermal comfort-related properties (airflow resistance and water vapor transmission rate) were also performed to discuss the balance between comfort and protection. These performances were analyzed based on the fabric characterization and the filtration theory. ${ }^{[19]}$ 


\section{MATERIALS AND METHODS}

\section{Fabrics}

Twenty common fabrics used for the manufacturing of protective clothing against solid aerosols were chosen (Table 1).

Table 1. Selected protective clothing.

\begin{tabular}{|c|c|c|c|}
\hline Protective clothing & Type of fabric & Material $^{\mathrm{A}}$ & Abbreviations \\
\hline $3 \mathrm{M} 4510$ & MP & $\mathrm{PE} / \mathrm{PP}$ & $3 \mathrm{M} 4510$ \\
\hline $3 \mathrm{M} 4520$ & SMS & PP & $3 \mathrm{M} 4520$ \\
\hline $3 \mathrm{M} 4530$ & SMS & PP & $3 \mathrm{M} 4530$ \\
\hline $3 \mathrm{M} 4540$ & MP & $\mathrm{PE} / \mathrm{PP}$ & $3 \mathrm{M} 4540$ \\
\hline Kimberly-Clark A10 & SMS & PP & $\mathrm{KC} \mathrm{A} 10$ \\
\hline Kimberly-Clark A20 & SMS & PP & $\mathrm{KC} \mathrm{A} 20$ \\
\hline Kimberly-Clark A30 & SMS & PP & $\mathrm{KC} \mathrm{A} 30$ \\
\hline Dupont Tyvek Xpert & FS & HD-PE & Tyvek \\
\hline Dupont Proshield NexGen & MP & $\mathrm{PE} / \mathrm{PP}$ & DPN \\
\hline Honeywell North Gen Pro & SMS & PP & NGP \\
\hline Honeywell North Gen Air & MP & $\mathrm{PE} / \mathrm{PP}$ & NGA \\
\hline Käppler ProVent 10000 & MP & $\mathrm{PE} / \mathrm{PP}$ & KP 10000 \\
\hline Lakeland Safeguard & SMS & PP & LSG \\
\hline Lakeland Micromax NS & MP & $\mathrm{PE} / \mathrm{PP}$ & LMX \\
\hline Portwest ST 30 & SMS & $\mathrm{PP}$ & ST 30 \\
\hline Portwest ST 40 & MP & $\mathrm{PE} / \mathrm{PP}$ & ST 40 \\
\hline Alphatec Microchem 1500 & SMS & PP & M 1500 \\
\hline Alphatec Microchem 1500FR & SMS & PP & M 1500FR \\
\hline Alphatec Microchem 1800 & MP & $\mathrm{PE} / \mathrm{PP}$ & M 1800 \\
\hline Alphatec Microchem 2000 & MP & $\mathrm{PE} / \mathrm{PP}$ & M 2000 \\
\hline
\end{tabular}

A PE: Polyethylene / PP: Polypropylene / HD: High Density 
Ten of them were made of an assembly of at least one meltblown layer (M layer) between two spunbonded layers (S layers), usually referred to as SMS (Spunbond/Meltblown/Spunbond). Nine of them were an assembly of one or several spunbonded layers with one microporous film, usually referred to as microporous (MP). The remaining fabric was a single layer made of flash-spun fibers (FS).

\section{Measurement of Particle Penetration Through Fabrics}

\section{Wind Tunnel}

A $1.4 \mathrm{~m}$ long, open-jet wind tunnel with a $400 \mathrm{~cm}^{2}$ cross-section $(20 \mathrm{x} 20 \mathrm{~cm})$ was built. The wind speed in the tunnel $\left(\mathrm{U}_{\mathrm{T}}\right)$ generated by a fan (FX 5 XL, Fantech, Sarasota, Florida, USA) was about $0.3 \mathrm{~m} / \mathrm{s}$ (720 1/min). A $17 \mathrm{~cm}$ diameter circular penetration cell, $15 \mathrm{~cm}$ long was placed in the wind tunnel, perpendicular to the airstream, to secure fabrics to be tested. The area of this $17 \mathrm{~cm}$ sample holder represents $56.7 \%$ of the tunnel cross-section. Details about this experimental setup are reported as supplemental information (Figure S1).

The sodium chloride $(\mathrm{NaCl})$ test aerosol was generated by a six-jet Collison Nebulizer (BGI by Mesa Labs, Butler, New Jersey, USA) using a 2.7\% $\mathrm{NaCl}$ solution at 2.07 bars (30 PSI). It was charge neutralized (Aerosol neutralizer 3012, TSI, Shoreview, Minnesota, USA) and dried with silica gel before being injected into the tunnel $65 \mathrm{~cm}$ downstream of the fan, through two face-to-face holes, and perpendicularly to the wind direction. The investigated particle sizes ranged from $20 \mathrm{~nm}$ to $3000 \mathrm{~nm}$. The particle size distribution of the generated aerosol is presented in Figure S2 as supplemental information. It was measured with a Scanning Mobility Particle Sizer (SMPS) for 
particles less than $600 \mathrm{~nm}$ in diameter (SMPS 3936, TSI, Shoreview, Minnesota, USA) and an Aerodynamic Particle Sizer (APS) for particles between 600 and $3000 \mathrm{~nm}$ (UVAPS 3314, TSI, Shoreview, Minnesota, USA). The cross-sectional uniformity of the air velocity and particle concentration was verified following the guidelines of ASHRAE standard 52.2-2012 ${ }^{[20]}$ (See Table S1 and S2 in supplemental information for particle concentration and air velocity).

\section{Fabric Face Velocities for Testing}

A modeling study of air velocities around a cylinder supposed to represent the human body ${ }^{[21]}$ showed that fabric face velocities for highly permeable clothing materials do not exceed $0.8 \mathrm{~cm} / \mathrm{s}$ for wind speeds up to $1.4 \mathrm{~m} / \mathrm{s}$. Another study ${ }^{[22]}$ showed that $85 \%$ of air velocities in indoor workplaces (asbestos removal enclosure, bakery, laboratory, wood cutting area...) were below $0.3 \mathrm{~m} / \mathrm{s}$. According to the results of Brasser, ${ }^{[20]}$ such a wind speed would lead to a fabric face velocity of $0.17 \mathrm{~cm} / \mathrm{s}$ for highly permeable fabrics. Thus, fabric face velocities were set at $0.05,0.15$, and $0.30 \mathrm{~cm} / \mathrm{s}$ for testing the penetration of particles through the fabrics.

\section{Penetration Measurements}

During penetration tests, relative humidity and temperature were about $25 \%$ and $20^{\circ} \mathrm{C}$, respectively. The previously described SMPS/APS coupling was used to measure particle concentrations and distributions upstream and downstream of the tested fabrics. To compensate for low fabric face velocities, a flow of clean compressed air (Flowmeter Model 4043, TSI, Shoreview, Minnesota, USA) was added to the sample flow to reach the set points of both SMPS and APS (0.3 1/min and $5 \mathrm{l} / \mathrm{min}$, respectively). 
The upstream and downstream particle-size distributions were measured at the center of the tunnel cross-section, with a sampling probe approximately located $20 \mathrm{~cm}$ before the fabric set on the penetration cell and $7 \mathrm{~cm}$ after the fabric, respectively.

The filtration performances are expressed in terms of collection efficiency. Since only protective clothing fabrics were tested in this study, the collection efficiency will be referred to as protection efficiency in this article. The protection efficiencies were calculated based on the upstream and downstream concentrations measured with the previously described SMPS/APS coupling for each size bin of these particle counters. The sequence of this upstream and downstream sampling was based on standard EN $779,{ }^{[23]}$ dedicated to establishing the performance of filters (See Table S3 in supplemental information). For each fabric, three samples were tested at the three selected fabric face velocities.

\section{Measurement of Comfort Indicators}

In this study, two fabric parameters considered to be indicative of comfort for the wearer were chosen. The first one is the airflow resistance representing the air permeability of a fabric. Thus, the lower the airflow resistance, the greater the chances of comfort. The other fabric parameter taken into account for comfort evaluation is the water vapor transmission rate representing the moisture permeability and thus the ability of a fabric to evacuate the human-source moisture. The water vapor transmission rate must be maximized to improve the level of comfort. 


\section{Air Permeability: Airflow Resistance}

The pressure drop generated by a porous media is described by Darcy's law as:

$$
\Delta \mathrm{P}=\frac{1}{\mathrm{~K}} \cdot \mu \cdot \mathrm{U}_{\mathrm{f}} \cdot \mathrm{Z}
$$

Where $\Delta \mathrm{P}$ is the pressure drop $(\mathrm{Pa}), \mathrm{K}$ is the intrinsic permeability of the porous media material $\left(\mathrm{m}^{2}\right), \mu$ is the dynamic viscosity of the carrier fluid $(\mathrm{Pa} \cdot \mathrm{s}), \mathrm{U}_{\mathrm{f}}$ is the fabric face velocity $(\mathrm{m} / \mathrm{s})$, and $\mathrm{Z}$ is the thickness of the porous media $(\mathrm{m})$. Since pressure drop is a function of both intrinsic permeability and media thickness, the ratio of these two properties, $\mathrm{Z} / \mathrm{K}$, was used to compare different media types. This ratio will be referred to as the hydraulic resistivity. According to Equation 1, the hydraulic resistivity can be easily calculated after measuring the pressure drop generated by a known airflow rate through a fabric of known area. The pressure drop measurements were performed with a 0-250 $\mathrm{Pa}$ and a 0-1000 Pa sensor interfaced with a data logger (Almemo 2290, Ahlborn, Holzkirchen, Germany) for the SMS fabrics and the Tyvek®. Due to their higher airflow resistance, a 0-5000 Pa inclined differential manometer (Type 4, Airflow developments, High Wycombe, UK) was used for the microporous fabrics. The airflow rate was measured with a 0-20 1/min mass flowmeter (4140, TSI, Shoreview, Minnesota, USA).

\section{Moisture Permeability: Water Vapor Transmission Rate}

The water vapor transmission rate expressed in $\mathrm{g} / \mathrm{m}^{2} /$ day was measured following the ASTM-like F2298 standard. ${ }^{[24]}$ This method uses a dynamic moisture permeation cell (DMPC) exposing the two faces of a $10 \mathrm{~cm}^{2}$ sample to co-current airflows differing from each other by their relative humidity. The difference in relative humidity was $90 \%$ (95\%- 
5\%). A pressure difference is also applied between the two faces of the garments. This pressure difference is increased gradually from $-150 \mathrm{~Pa}$ to $150 \mathrm{~Pa}$. Then, at the exit of the DMPC, the relative humidity of the two airflows is measured again, the changes in relative humidity in these flows enabling the calculation and the plotting of a water vapor flux as a function of the pressure difference. The y-axis intercept of the obtained curve is considered to be the water vapor transmission rate. This data is therefore representative of the diffusional water vapor flux.

\section{Fabric Characterization}

Except for the Tyvek®, all the fabrics are composed of several layers, only one of which acts as an efficient particle filter: the upper microporous film for MP garments and the middle meltblown layer for the SMS fabrics. Thus, the characterization of the different materials can be considered at two levels: the whole fabric and the filtering layer.

\section{Fabric Thickness}

The total thickness of the protective clothing materials was measured following standard CAN/CGSB-4.2 No. 37-2002. ${ }^{[25]}$ This standard, developed for compressible textile fabrics, consists in applying an arbitrary pressure (1000 Pa) on the tested sample between plane surfaces.

\section{Meltblown Layer Thickness}

It was not possible to use the same standard for measuring the thicknesses of meltblown layers because layers of the SMS assemblies cannot be separated without 
being damaged or modified. The meltblown layer thicknesses were then measured on cross-sectional images of SMS samples. These photos were taken with a stereomicroscope (SMZ-18, Nikon Instruments Inc., Tokyo, Japan) providing a large enough observation distance and magnification, i.e., 135x. For these observations, the samples were inserted between microscope and cover slides to hold them without significant compression. After acquisition, the images were automatically analyzed with a MATLAB® (Mathworks, Natick, Massachusetts, USA) code detecting and measuring the M layer thickness.

\section{Fiber Diameter}

Fiber diameters were measured for the SMS fabrics and spunbonded layer of the microporous materials. The measurements were performed using photographs taken by optical microscopy (Nikon Eclipse E400, Nikon Instruments Inc., Tokyo, Japan) set at 400x magnification. Some 100 measurements per fabric were performed with the ImageJ software (National Institutes of Health, Bethesda, Maryland, USA). In the case of the SMS materials, measurements were performed on the two spunbonded layers (outer and inner layers) and on the M layer.

\section{Fabric Porosity}

Once the fabric thickness is known, the fabric porosity can be calculated by measuring the surface density and the density of the fabrics using standards CAN/CGSB4.2 No./ $\mathrm{N}^{\circ} 5.1-\mathrm{M} 90^{[26]}$ and ASTM D792-08, ${ }^{[27]}$ respectively. 
The fabric porosity is given by Equation 2:

$$
\epsilon_{\mathrm{T}}=1-\frac{\mathrm{W}}{\left(\rho_{\mathrm{f}} \cdot \mathrm{Z}_{\mathrm{T}}\right)}
$$

in which $\mathrm{W}$ is the surface density $\left(\mathrm{kg} / \mathrm{m}^{2}\right), \mathrm{Z}_{\mathrm{T}}$ is the thickness of the fabric $(\mathrm{m})$, and $\rho_{\mathrm{f}}$ is the fabric material $\left(\mathrm{kg} / \mathrm{m}^{3}\right)$.

\section{Meltblown Layer Porosity}

The calculation of the meltblown layer porosity were based on the use of the Davies pressure drop equation ${ }^{[28]}$ for fibrous media (Equation 3):

$$
\Delta \mathrm{P}_{\mathrm{M}}=\frac{1}{\mathrm{~K}_{\mathrm{M}}} \cdot \mu \cdot \mathrm{U} \cdot \mathrm{Z}_{\mathrm{M}}=\frac{64 \cdot\left(1-\epsilon_{\mathrm{M}}\right)^{\frac{3}{2}} \cdot\left(1+56 \cdot\left(1-\epsilon_{\mathrm{M}}\right)^{3}\right)}{\mathrm{d}_{\mathrm{f}, \mathrm{M}}^{2}} \cdot \mu \cdot \mathrm{U}_{\mathrm{f}} \cdot \mathrm{Z}_{\mathrm{M}}
$$

With $\Delta \mathrm{P}_{\mathrm{M}}$ being the $\mathrm{M}$ layer pressure drop $(\mathrm{Pa}), \mathrm{K}_{\mathrm{M}}$ the $\mathrm{M}$ layer intrinsic permeability $\left(\mathrm{m}^{2}\right), \epsilon_{\mathrm{M}}$ the $\mathrm{M}$ layer porosity, $\mathrm{d}_{\mathrm{f}, \mathrm{M}}$ the $\mathrm{M}$ fiber diameter $(\mathrm{m}), \mu$ the dynamic viscosity (Pa.s), $U_{\mathrm{f}}$ the fabric face velocity $(\mathrm{m} / \mathrm{s})$, and $\mathrm{Z}_{\mathrm{M}}$ the $\mathrm{M}$ layer thickness $(\mathrm{m})$.

Since $d_{f, M}, U_{f}, Z_{M}$ and $\mu$ are known, the $M$ layer porosity $\epsilon_{M}$ could be calculated as long as the $\mathrm{M}$ layer pressure drop $\Delta \mathrm{P}_{\mathrm{M}}$ could be measured. Since the meltblown layers could not be separated from the $\mathrm{S}$ layers, $\Delta \mathrm{P}_{\mathrm{M}}$ could not be measured directly. It was hypothesized that, since the particle collection is supposed to be predominantly due to the M layer, the pressure drop of the fabric was also being predominantly due to the M layer

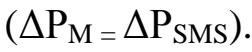


This hypothesis could be verified using Davies' model (Equation 3) to express the measured fabric pressure drop as the sum of the pressure drops in the $\mathrm{S}$ and $\mathrm{M}$ layers (Equation 4).

$$
\Delta \mathrm{P}_{\mathrm{SMS}}=\frac{64 \cdot\left(1-\epsilon_{\mathrm{M}}\right)^{\frac{3}{2}} \cdot\left(1+56 \cdot\left(1-\epsilon_{\mathrm{M}}\right)^{3}\right)}{\mathrm{d}_{\mathrm{f}, \mathrm{M}}^{2}} \cdot \mu \cdot \mathrm{U}_{\mathrm{f}} \cdot \mathrm{Z}_{\mathrm{M}}+\frac{\mathrm{Z}_{\mathrm{S}}}{\mathrm{K}_{\mathrm{S}}} \cdot \mu \cdot \mathrm{U}_{\mathrm{f}}
$$

With $\Delta \mathrm{P}_{\mathrm{SMS}}$ being the whole material measured pressure drop $(\mathrm{Pa}), \mathrm{K}_{\mathrm{S}}$ the intrinsic permeability $\left(\mathrm{m}^{2}\right)$ of the two $S$ layers, and $Z_{S}$ their thickness $(m) . d_{f, M}, U_{f}, Z_{M}$ and $\mu$ being known and $\mathrm{Z}_{\mathrm{S}}$ being calculated from the difference between the whole material and the $\mathrm{M}$ layer thicknesses, only $K_{S}$ has to be determined to evaluate $\epsilon_{M}$, the $M$ layer's porosity. $K_{S}$ was measured following the method described earlier for the airflow resistance evaluation, using five separated S layers from microporous films (M 1800, M 2000, ST 40, NGA and LMX). Thus, this approach assumed that the S layers from all the fabrics, SMS and MP, were similar. This assumption was supported by our measurements, showing that 15 out of the 18 garments have $S$ fiber diameters ranging from $17 \mu \mathrm{m}$ to 20 $\mu \mathrm{m}$.

A good agreement between $\epsilon_{M}$ values obtained from Equations 3 and 4 would tend to confirm the assumption of a negligible contribution from the S layer to the SMS fabrics pressure drop.

\section{Pore Size Distribution}

The pore size distribution of the whole material was measured according to standard ASTM D6767-16, ${ }^{[29]}$ relative to pore size characterization of geotextiles by 
capillary flow test. It indicates the pore size below which there is a defined pore fraction $(98 \%, 95 \%, 90 \%, 85 \%, 60 \%, 50 \%, 30 \%, 15 \%, 10 \%$ and $5 \%)$. The smallest pore diameter measurable by this method is $1 \mu \mathrm{m}$.

\section{RESULTS AND DISCUSSION}

\section{Protection Efficiency}

When measured at three different fabric face velocities, the results of the measured protection efficiencies highlighted the separation of the 20 protective fabrics into three distinct groups: low (Group A - square markers in Fig. 1 - minimum protection efficiency around 0.50), medium efficiency (Group B - circular markers in Fig. 1 minimum protection efficiency around 0.75), and very high efficiency (Group C triangular markers in Fig. 1 - minimum protection efficiency around 0.95). Figure 1 illustrates these groupings at a fabric face velocity of $0.3 \mathrm{~cm} / \mathrm{s}$.

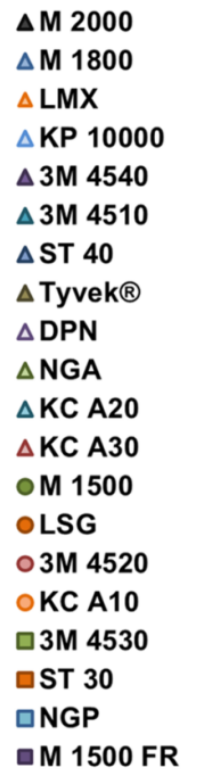

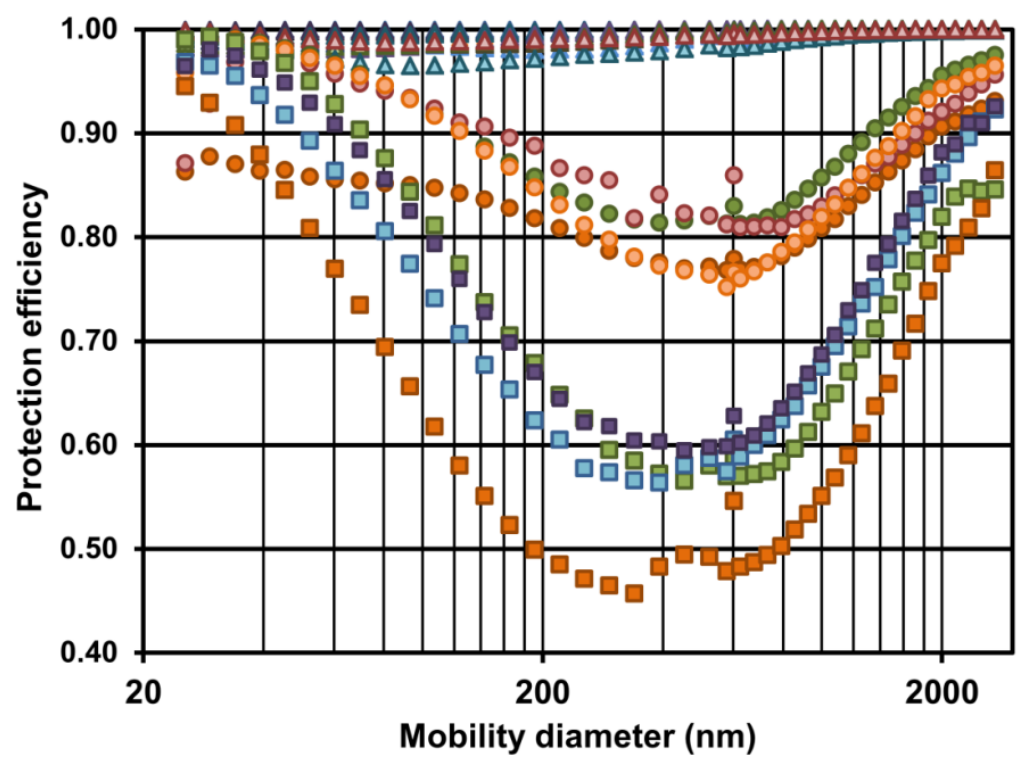

Figure 1. Protection efficiency of the 20 protective clothing (Fabric face velocity $0.3 \mathrm{~cm} / \mathrm{s}$ - Square markers: Gr. A / Circular markers: Gr. B / Triangular markers: Gr. C). 
According to Figure 1, Groups A and B are composed of four SMS fabrics (3M 4530, M 1500FR, ST 30, NGP and 3M 4520, M 1500, KC A10, LSG) and Group C is a combination of two SMS, nine microporous and one flash spun fabric (KC A20, KC A30, ST 40, M 1800, M 2000, KP 10000, LMX, DPN, NGA, 3M 4510, 3M 4540, Tyvek®). Two other facts were also noticed on Figure 1: (1) the very flat efficiency curve of the LSG in the diffusional regime and (2) the significantly lower efficiency of the ST 30 fabric compared to the other Group A materials. This was observed for the three fabric face velocities. The composition of the three groups of protection efficiency remaining unchanged for all the tested fabric face velocities, a more convenient way of displaying and comparing the results was to represent the average protection efficiency of each group with the standard deviation as error bars (Figure 2). For Groups A and B, the typical particle filtration medium behavior was observed, i.e. an increase in collection efficiency as the fabric face velocity decreases, especially for the smallest particles due to the enhancement of the collection by Brownian diffusion, as well as an increase of the most penetrating particle size (MPPS) still between $300 \mathrm{~nm}$ and $700 \mathrm{~nm}$.

This is more visible on Figures 3-a and 3-b, showing the minimum protection efficiency and the MPPS of all A and B cluster materials. However, Figure 3-b reveals an exception, the LSG MPPS appeared to strongly decrease at low fabric face velocity. Nevertheless, this last point must be tempered by the fact that these are mathematical MPPS obtained by derivative function inversions introducing uncertainties for this kind of flat efficiency profile. 

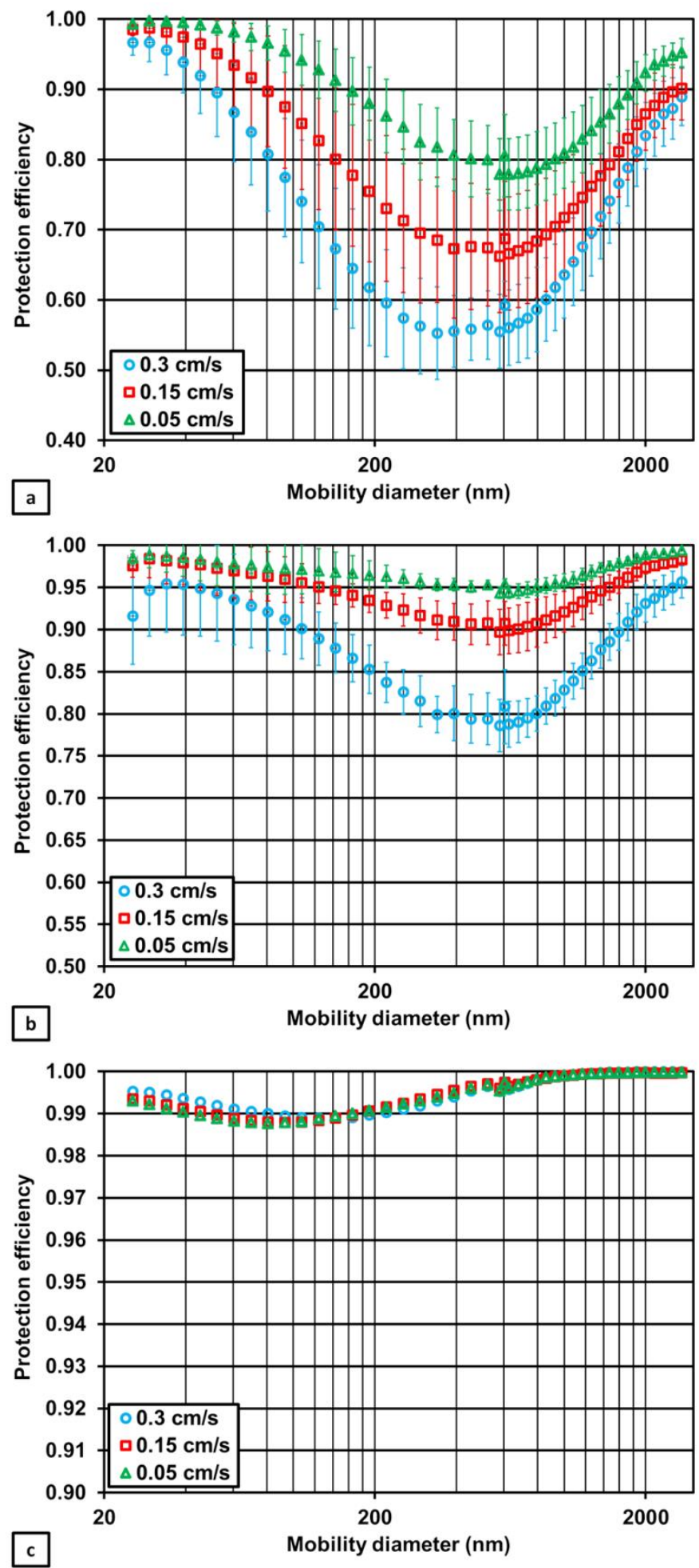

Figure 2. Protection efficiency of the three groups of Type-5 protective clothing at three different fabric face velocities (a: Gr. A, b: Gr. B, c: Gr. C). 

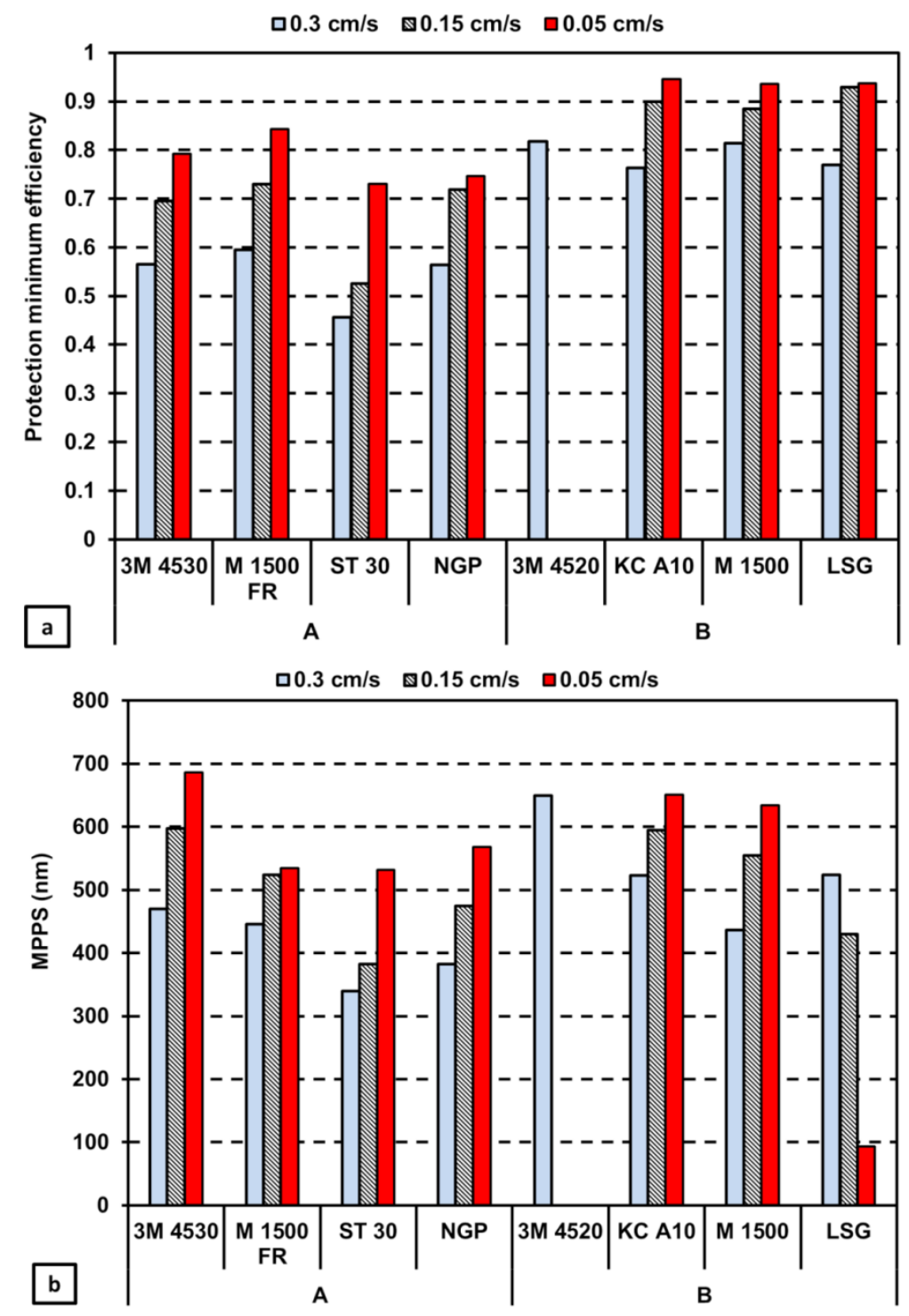

Figure 3. a: MPPS Protection efficiency of A and B cluster garments / b: MPPS for $\mathrm{A}$ and $\mathrm{B}$ cluster garments. ${ }^{\mathrm{B}}$

Group $\mathrm{C}$ being composed of various kinds of fabrics, its behaviour, except concerning its close to 1 protection efficiency, cannot be precisely described by this clustered display. As shown in Figure 4-a, six of the nine MP materials (3M 4510, DPN, LMX, M 1800, M 2000, ST 40) showed a slight drop in the minimum protection efficiency instead of an increase, two remained constant (3M 4540, NGA) and only one

\footnotetext{
${ }^{B}$ For the $3 M 4520$ fabric, only data at $0.3 \mathrm{~cm} / \mathrm{s}$ are available because of an experimental issue.
} 
(KP 10000) behaved as expected with an increase of its minimum collection efficiency as the fabric face velocity decreased.
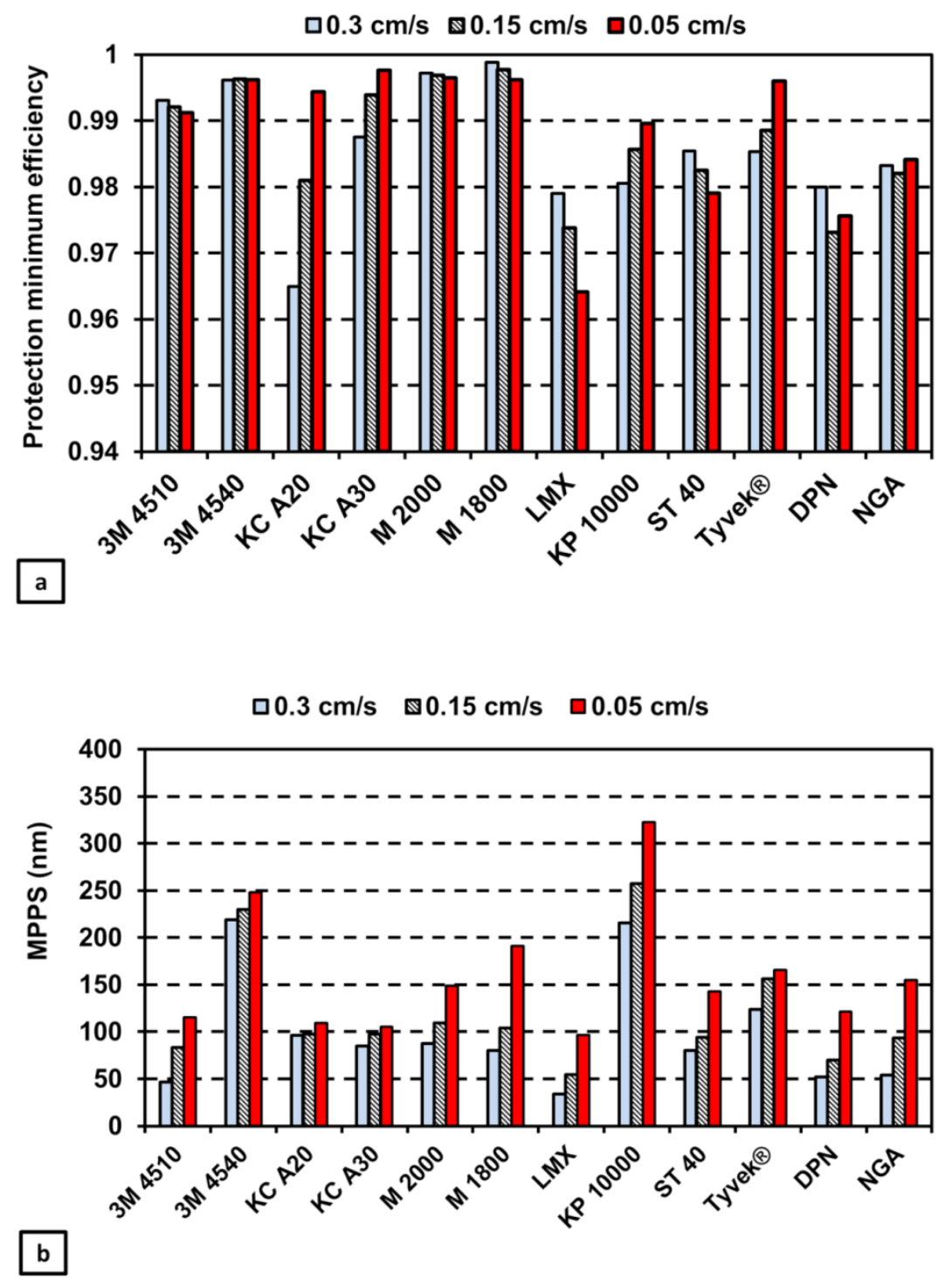

Figure 4. a: MPPS Protection efficiency of C cluster garments / b: MPPS for C cluster garments.

If the minimum protection efficiency of microporous fabrics often did not follow the expected trend, their MPPS increased as the fabric face velocity decreases as predicted by the filtration theory. However, MPPS values were significantly smaller than those obtained for classical fibrous media such as the SMS fabrics of the A and B 
Groups. In this article, the term "classical fibrous media" is used to describe fibrous media that do not provide enhanced collection efficiency by electrostatic effects such as electret filters. Indeed, with the exception of one microporous fabric (KP 10000), all the MPPS were below $250 \mathrm{~nm}$. For the other types of materials belonging to Group C (one flash spun (Tyvek®) and two SMS fabrics (KC A20 and KC A30)), Figures 4-a and 4-b highlight an expected qualitative behaviour, i.e., a decrease in protection efficiency and MPPS values as the fabric face velocity increases. Quantitatively, MPPS values were again smaller than those of classical fibrous media (below $200 \mathrm{~nm}$ ).

Because of the lack of identification of tested fabrics in the literature, an accurate comparison of their performances with the results of this study appears to be difficult. Indeed, previous studies dealt with a narrower particle size range,${ }^{[16-18]}$ larger fabric face velocities, or expressed the protection efficiency as global and not size-dependent. ${ }^{[15]}$ Nevertheless, the results of two studies could partially be compared to those obtained in this work. Among the ten samples tested by Gao et al.. ${ }^{[17]}$ one could be identified as a fabric (SMS) from a coverall protective clothing. In addition, some of their fabric face velocities are very close to those used in this work: $0.25 \mathrm{~cm} / \mathrm{s}$ and $0.37 \mathrm{~cm} / \mathrm{s}$. For these velocities and for particles ranging from $30 \mathrm{~nm}$ to $500 \mathrm{~nm}$ in diameter, the results of Gao et al. appeared to compare satisfactorily with the protection efficiency of the Group A measured at $0.3 \mathrm{~cm} / \mathrm{s}$. Despite a larger fabric face velocity, these article results are also consistent with those of Salah et al. ${ }^{[14]}$ (particle size range from $15 \mathrm{~nm}$ to $400 \mathrm{~nm}$ and fabric face velocity of $0.435 \mathrm{~cm} / \mathrm{s})$. Thus, Salah et al. highlighted the very high efficiency of microporous and flashspun fabrics. Their data for two SMS fabrics are also in agreement with this article, showing possibly a Group B SMS having a lower efficiency 
because of a larger fabric face velocity and a Group C SMS with a very high level of protection and a MPPS around $100 \mathrm{~nm}$.

\section{Comfort Indicators}

Airflow Resistance

As stated in the materials and methods sections, hydraulic resistivity was chosen as an indicator of the fabric air permeability. Thus, the lower the airflow resistance, the greater the chances of comfort. Similar to the protection efficiency, three groups of airflow resistance were revealed (Table 2). These groups are somewhat different and correspond to the three types of protective clothing materials: Flash Spun (FS), Microporous (MP) and Spunbond/ Meltblown/ Spunbond (SMS). As intuitively thought, microporous fabrics having the highest protection efficiencies appear to also have, by far, the highest hydraulic resistivity, i.e., about 10,000 and 100 times greater than the SMS and flash spun materials, respectively.

\section{Water Vapor Transmission Rate}

By analogy with the airflow resistance, water vapor transmission rate was chosen as an indicator of the human-source moisture control. According to this definition, this parameter must be maximized to improve the level of comfort. The moisture control parameter appeared almost to correlate with air permeability evaluation (Table 2). Indeed, SMS fabrics generating the smallest airflow resistance have a greater water vapor transmission rate and MP materials appear again by far to be the least permeable to water vapor. It must also be noticed that, as opposed to airflow resistance, the water vapor 
transmission rate of the FS material is of the same order of magnitude as the MP garments.

Only few studies provide information about comfort indicators. Nevertheless, once converted to hydraulic resistivity, the value of air permeability given by Gao et al. ${ }^{[17]}$ for their SMS fabric correlates well with the results presented in Table 2 for the same kind of materials.

Table 2. Measurement results of hydraulic resistivity, water vapor transmission rate, $\mathrm{M}$ layer porosity and total fabric porosity of the 20 selected protective clothing.

\begin{tabular}{|c|c|c|c|c|c|c|}
\hline VPC & $\begin{array}{l}\text { Type, } \\
\text { group }\end{array}$ & $\begin{array}{c}\text { Hydraulic } \\
\text { resistivity } \\
\text { (/m) }\end{array}$ & $\begin{array}{c}\text { Water vapor } \\
\text { transmission } \\
\text { rate } \\
\left(\mathrm{g} / \mathrm{m}^{2} / \mathrm{day}\right)\end{array}$ & $\begin{array}{l}\text { M layer } \\
\text { porosity } \\
\left(\Delta \mathbf{P}_{\mathrm{M}}=\Delta \mathbf{P}_{\text {SMS }}\right)\end{array}$ & $\begin{array}{c}\text { M layer } \\
\text { porosity } \\
\left(\Delta \mathbf{P}_{\mathrm{M}}=\right. \\
\left.\Delta \mathbf{P}_{\mathrm{S}}+\Delta \mathbf{P}_{\mathrm{M}}\right)\end{array}$ & $\begin{array}{c}\text { Total } \\
\text { fabric } \\
\text { porosity }\end{array}$ \\
\hline Tyvek® & FS, C & $2.63 \mathrm{E}+09$ & 5983 & - & - & 0.764 \\
\hline M 2000 & $\mathrm{MP}, \mathrm{C}$ & $1.90 \mathrm{E}+11$ & 6814 & - & - & 0.787 \\
\hline M 1800 & $\mathrm{MP}, \mathrm{C}$ & $3.10 \mathrm{E}+11$ & 3367 & - & - & 0.797 \\
\hline LMX & $\mathrm{MP}, \mathrm{C}$ & $6.52 \mathrm{E}+11$ & 3721 & - & - & 0.777 \\
\hline KP 10000 & $\mathrm{MP}, \mathrm{C}$ & $7.02 \mathrm{E}+10$ & 6179 & - & - & 0.799 \\
\hline $3 M 4540$ & $\mathrm{MP}, \mathrm{C}$ & $1.28 \mathrm{E}+11$ & 5831 & - & - & 0.772 \\
\hline $3 M 4510$ & $\mathrm{MP}, \mathrm{C}$ & $1.96 \mathrm{E}+11$ & 5189 & - & - & 0.807 \\
\hline ST 40 & $\mathrm{MP}, \mathrm{C}$ & $1.91 \mathrm{E}+11$ & 4480 & - & - & 0.795 \\
\hline DPN & $\mathrm{MP}, \mathrm{C}$ & $2.70 \mathrm{E}+11$ & 4895 & - & - & 0.810 \\
\hline NGA & $\mathrm{MP}, \mathrm{C}$ & $4.96 \mathrm{E}+11$ & 2672 & - & - & 0.773 \\
\hline M 1500 FR & SMS, A & $3.03 \mathrm{E}+07$ & 13424 & 0.730 & 0.741 & 0.828 \\
\hline $3 \mathrm{M} 4530$ & SMS, A & $2.22 \mathrm{E}+07$ & 14557 & 0.805 & 0.819 & 0.810 \\
\hline ST 30 & SMS, A & $2.66 \mathrm{E}+07$ & 13052 & 0.703 & 0.715 & 0.834 \\
\hline NGP & SMS, A & $2.37 \mathrm{E}+07$ & 15311 & 0.773 & 0.786 & 0.847 \\
\hline LSG & SMS, B & $7.41 \mathrm{E}+06$ & 15081 & 0.848 & 0.889 & 0.849 \\
\hline $3 M 4520$ & SMS, B & $2.59 \mathrm{E}+07$ & 12948 & 0.812 & 0.822 & 0.851 \\
\hline M 1500 & SMS, B & $3.49 \mathrm{E}+07$ & 12979 & 0.796 & 0.804 & 0.831 \\
\hline KC A10 & SMS, B & $2.01 \mathrm{E}+07$ & 12508 & 0.826 & 0.839 & 0.851 \\
\hline KC A20 & SMS, C & $2.96 \mathrm{E}+07$ & 14196 & 0.777 & 0.786 & 0.849 \\
\hline KC A30 & SMS, C & $4.96 \mathrm{E}+07$ & 14339 & 0.731 & 0.738 & 0.839 \\
\hline
\end{tabular}




\section{Differences in Protection Efficiency}

\section{Groups A (except ST 30) and B (except LSG)}

Groups A and B show low and medium protection efficiency, respectively, and are only composed of SMS fabrics. From the characterization of the filtration layer (M layer) of these fabrics, no clear trend emerged concerning the factors governing the protection efficiency. Thus, for these two groups, the M fiber diameter ranges from $2 \mu \mathrm{m}$ to $2.5 \mu \mathrm{m}$ (Figure 5-a) without exhibiting a decreasing pattern from Group A to B, which would increase the collection efficiency. The same absence of correlation was obtained regarding the estimated $\mathrm{M}$ layer porosity varying between 0.7 and 0.85 (Table 2) without systematically being lower for Group B. As for the M layer's porosity, the data in Table 2 show that the two methods used for its calculation give similar results, indicating, as mentioned previously, the negligible effect of the S layers on the SMS fabrics' airflow resistance. The only parameter varying clearly in a similar way and which could explain the efficiency gap between Groups A and B appears to be the M layer thickness: close to $11 \mu \mathrm{m}$ and $16 \mu \mathrm{m}$ for Groups A and B, respectively (Figure 5-b). On average, the M layer thickness differs by a factor of 1.5 from one group to another. 

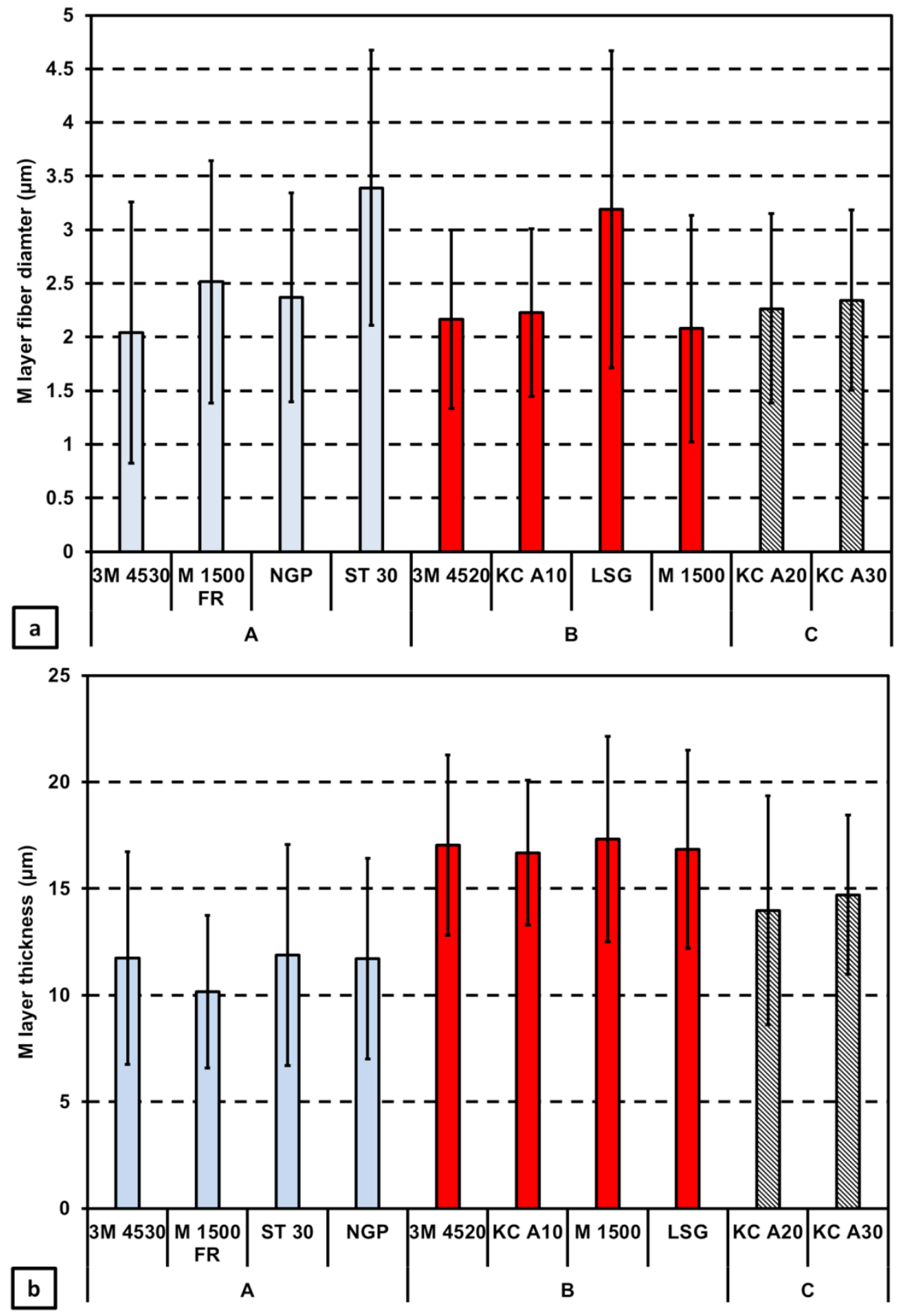

Figure 5. a: M layer fiber diameter of SMS fabrics / b: M layer thickness of SMS fabrics. 
To verify whether this increase in M layer thickness could effectively cause the change in efficiency from Group A to Group B, the collection efficiency of a virtual protective fabric was calculated on the basis of the Group A mean efficiency, considering that no other parameters changed except for the M layer thickness. The equation used for this calculation is the global efficiency law of fibrous filters. ${ }^{[19]}$ For Group A SMS, the protection efficiency $\mathrm{E}_{\mathrm{A}}$ is given by:

$$
E_{A}=1-\exp \left(-4 \cdot e_{f} \cdot \frac{1-\epsilon}{\epsilon} \cdot \frac{Z_{M, A}}{\pi \cdot d_{f}}\right)
$$

With $e_{\mathrm{f}}$ being the single fiber collection efficiency, $\epsilon$ the porosity of the fibrous media, $d_{f}$ the fiber diameter $(\mathrm{m})$, and $\mathrm{Z}_{\mathrm{M}, \mathrm{A}}$ the $\mathrm{M}$ layer thickness $(\mathrm{m})$. The same equation can be used to compute the virtual SMS efficiency, $\mathrm{E}_{\mathrm{Y}}$ :

$$
\mathrm{E}_{\mathrm{Y}}=1-\exp \left(-4 \cdot \mathrm{e}_{\mathrm{f}} \cdot \frac{1-\epsilon}{\epsilon} \cdot \frac{\mathrm{Y} \cdot \mathrm{Z}_{\mathrm{M}, \mathrm{A}}}{\pi \cdot \mathrm{d}_{\mathrm{f}}}\right)
$$

All parameters remained unchanged between Equations 5 and 6 except for the introduction of the $\mathrm{M}$ layer thickness factor, $\mathrm{Y}$, equal to 1.5 (ratio of the mean $\mathrm{Z}_{\mathrm{M}, \mathrm{B}}$ and $\mathrm{Z}_{\mathrm{M}, \mathrm{A}}$ values). By combining Equations 5 and 6, $\mathrm{E}_{\mathrm{Y}}$ can be expressed as:

$$
E_{Y}=1-\left(1-E_{A}\right)^{Y}
$$

If the difference in $\mathrm{M}$ layer thickness is indeed the main cause of the efficiency gap between Groups $\mathrm{A}$ and $\mathrm{B}$, then $\mathrm{E}_{\mathrm{Y}}$ should be close to Group B's mean collection efficiency. This can be observed in Figure 6 for a fabric face velocity of $0.3 \mathrm{~cm} / \mathrm{s}$ where mean relative errors do not exceed $10 \%$. On this figure, the dashed purple curves correspond to the virtual material efficiencies considering the mean geometric standard 
deviation of the M layer thickness measurements leading to 1.44 and 1.59 as $\mathrm{Y}$ values. For fabric face velocities of $0.15 \mathrm{~cm} / \mathrm{s}$ and $0.05 \mathrm{~cm} / \mathrm{s}$, this relative error is below $7 \%$ and $5 \%$, respectively (see Figure S3 in supplemental information).

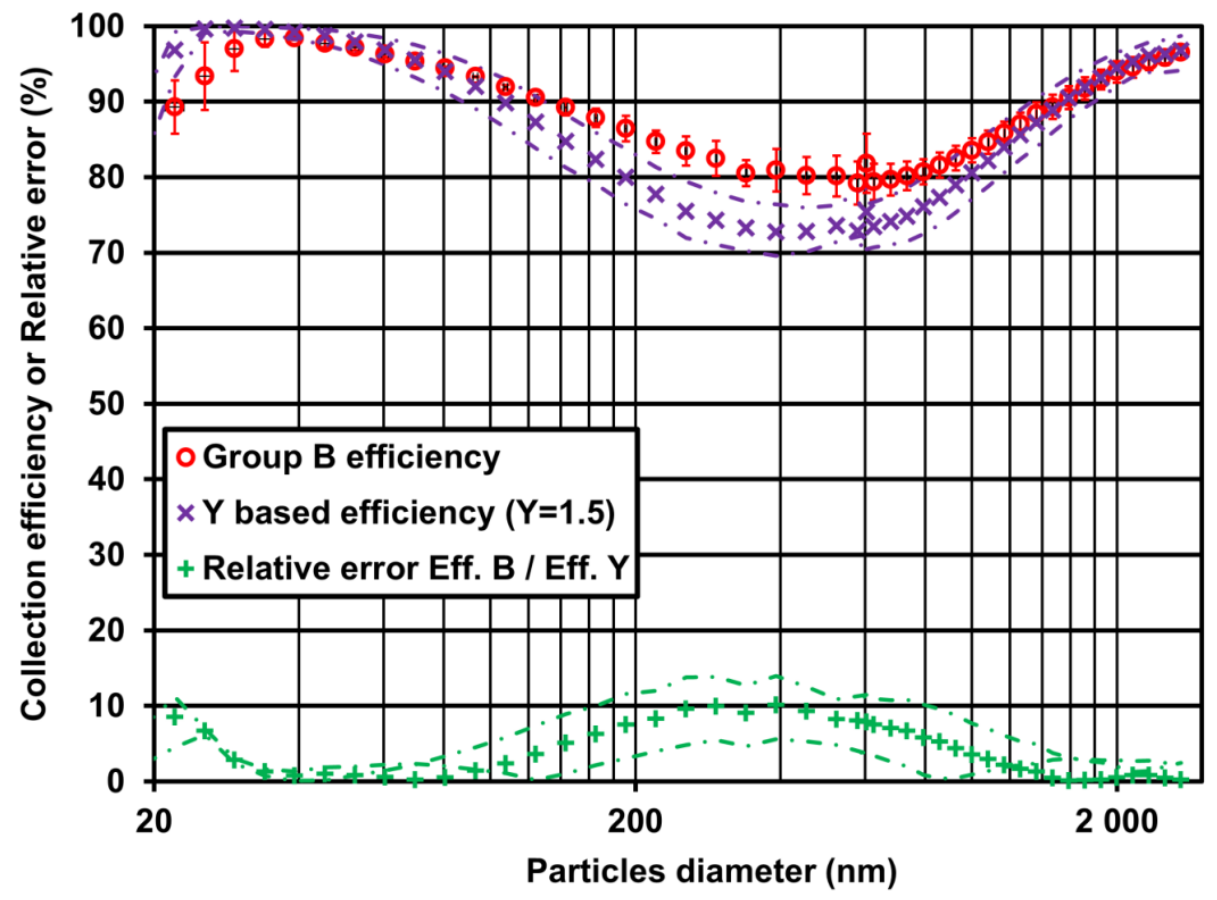

Figure 6. Comparison of the virtual protective clothing with the Group B fabrics assuming a $\mathrm{M}$ layer thickness of $\mathrm{Y} x \mathrm{Z}_{\mathrm{M}, \mathrm{A}}(\mathrm{Y}=1.5)$ for a fabric face velocity of $0.3 \mathrm{~cm} / \mathrm{s}$.

\section{LSG and ST 30 Fabrics}

Two SMS fabrics stood out of the general protection efficiency behavior observed for Group A and B: the LSG (Group B) and the ST 30 (Group A). LSG exhibits a flat protection efficiency profile in the diffusional regime and the submicron particle range. If no definitive explanation could be found yet, the fabric characteristics highlighted the unique structure of the LSG. The difference with the other SMS materials is especially noticeable in terms of $S$ and $M$ fiber diameters (Figure 5-a). Indeed, LSG S fibers are between $25 \%$ and $50 \%$ larger compared to other fabrics and $\mathrm{M}$ fibers are about $50 \%$ 
larger than those of almost all SMS (except ST 30). These larger fiber diameters might be one of the reasons for the greater pore size of the LSG (two times larger than other SMS materials) showed on Figure 7.

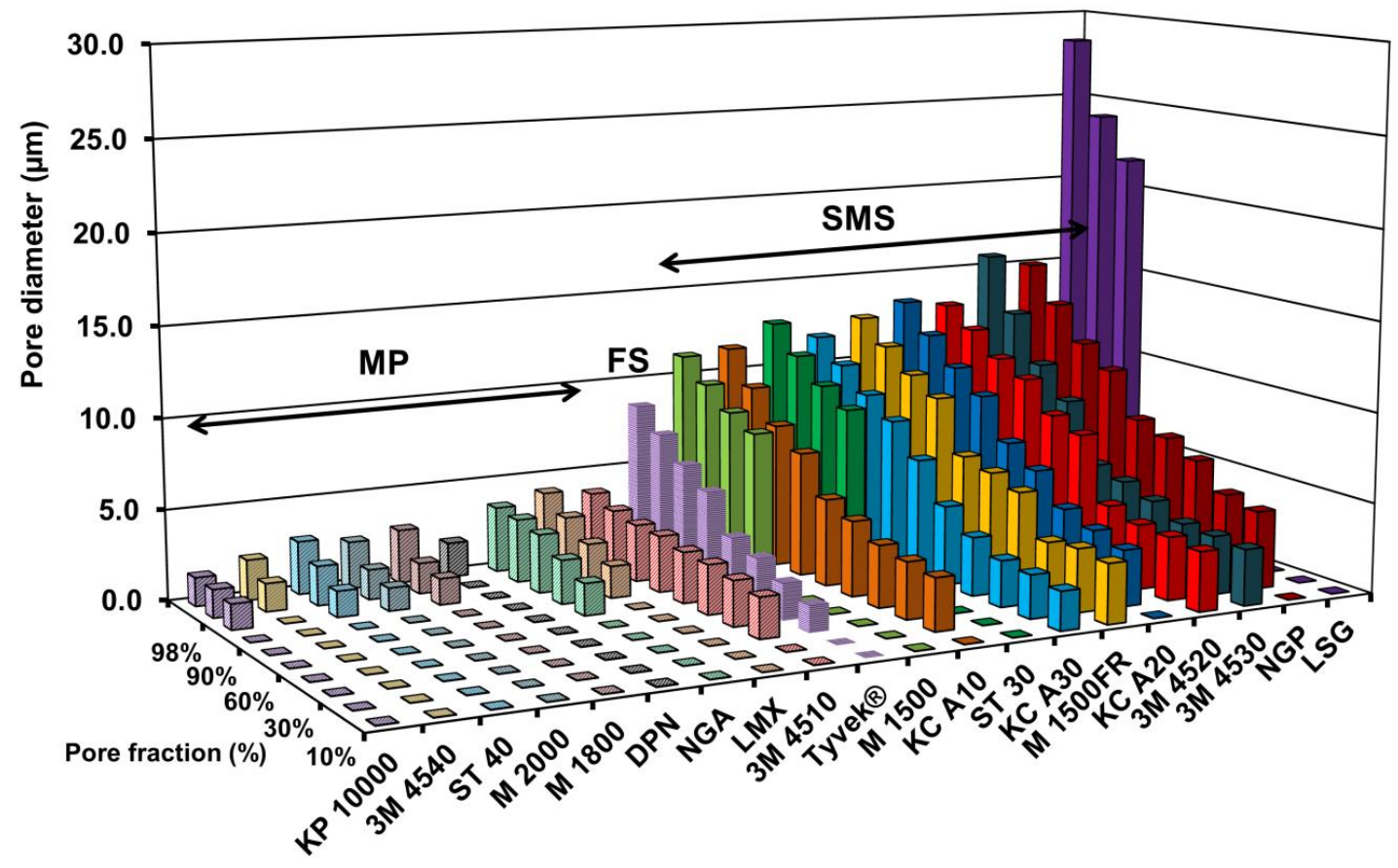

Figure 7. Pore diameter distribution of the 20 protective fabrics.

These larger pores could partially explain the lower collection efficiency of the Brownian particles compared to other SMS of Group B, but also the lowest airflow resistance among all the tested clothing (Table 2). However, this larger pore size still does not explain why only the Brownian particles collection efficiency seems to be altered and why the performances of the LSG belongs to Group B with medium efficiency. Indeed, all relevant parameters should imply equal (M layer thickness) or lower protection performances than the other Group B SMS (larger M layer porosity and M fiber diameter). A hypothesis to explain that behavior might be the presence of an unknown treatment of the fiber. 
Although assimilated to Group A SMS, ST 30 exhibits protection performances significantly lower than the other three (M 1500FR, 3M 4530 and NGP), i.e., efficiencies lower by between 10 and $20 \%$. This might be explained by the characterisation data. Indeed, for a same M layer thickness, ST 30 is made of the largest M fibers of the 20 tested fabrics, a larger fiber diameter not compensated for by a lower M layer porosity.

\section{Group C}

\section{- $\quad$ Microporous protective clothing}

As previously mentioned, Group $\mathrm{C}$ includes the three fabric types and exhibits very high protection efficiencies. It includes all the microporous fabrics, whose filtration layer is not made of fibers, but rather consists in a membrane with very fine pores. According to Figure 7, these pores are about 1 or $2 \mu \mathrm{m}$ in diameter, but they are certainly smaller given these values correspond to the measurement limit of the standard method used in this study. Indeed, slit shape pore dimensions as small as 20 to $40 \mathrm{~nm}$ wide by $200 \mathrm{~nm}$ to $400 \mathrm{~nm}$ long for this kind of microporous films were identified in the

literature. ${ }^{[30-31]}$ Added to these low pore sizes, the general lower fabric total porosity compared to the SMS materials (Table 2) also explains the high protection level of MP fabrics.

The pore size could also provide an explanation regarding the very small decrease or stability of the protection efficiencies with the decrease in fabric face velocity, observed for eight of the nine microporous garments and represented by the MPPS protection efficiencies shown on Figure 4-a. The very small sized pores, by generating very large pressure drops, could create a low-pressure atmosphere in the MP films. 
Indeed, using Darcy's law (Equation 2) and the previously calculated MP fabrics' hydraulic resistivity, these pressure drops were found to be up to $17 \%$ of a normal atmospheric pressure for a fabric face velocity of $0.3 \mathrm{~cm} / \mathrm{s}$. This could transform their internal solid fractions into low-pressure impactors due to a larger particle mean free path in air, increasing therefore by impaction the collection efficiency even of low inertia particles and thus compensating for the decrease in Brownian diffusion. According to the MP film pore size, impaction is also assisted by the high air velocity inside the pores and the very short impaction distances inside the MP films (between a few dozen and hundreds of $\mathrm{nm}$ ). Consistent with this assumption, and interestingly, the MP fabrics exhibiting this unexpected behaviour generate the larger pressure drops (mostly between 10 and $20 \%$ of a normal atmospheric pressure) while the KP 10000, showing an increase in collection efficiency as the fabric face velocity decreases, is the most air permeable MP material (pressure drop of about $4 \%$ of the normal atmospheric pressure). The MP fabrics showing approximately constant collection efficiencies for the three selected fabric face velocities are intermediates in terms of pressure drop (between 10 and 5\% of the normal atmospheric pressure). The assumption made previously could also be consistent with the observed low (mostly below $150 \mathrm{~nm}$ ) and increasing MPPS as the fabric face velocity decreases. Indeed, the low-pressure impaction could preferentially enhance the collection of $200 \mathrm{~nm}$ to $600 \mathrm{~nm}$-diameter particles compared to the ultrafine particles (below $100 \mathrm{~nm}$ ). Another contribution to this low MPPS could also be the sieving effect created by the very small pores. 
Compared to SMS fabrics, the MP structural properties are also consistent with the results of the comfort-assessment measurements, namely, four orders of magnitude larger for airflow resistance and the water vapor transmission rate lower by almost half.

\section{- $\quad$ Flash Spun protective clothing (Tyvek®)}

FS material (Dupont Tyvek®) is also included in Group C; it is also the only monolayer fabric, meaning its entire thickness, about $226 \mu \mathrm{m}$, performs aerosol filtration. Since this material is not made of clearly definable fibers, only a larger useful filtration thickness, an intermediate pore size compared to MP and SMS fabrics and one of the lowest filtration layer porosities (about 76\%) could explain its high level of protection efficiency (above 98.5\%), but also its intermediate performance in terms of airflow resistance (about $10^{9} \mathrm{~m}^{-1}$ ). Although this is also consistent with Tyvek® having a lower water vapor transmission rate compared to SMS materials, these properties do not explain why almost no difference was observed with that of MP fabrics.

\section{- Spunbond/Meltblown/Spunbond protective clothing}

The last two protective fabrics included in Group C are the SMS KC A20 and KC A30. From a characterization standpoint, these are not very different from the other SMS. Indeed, compared to SMS fabrics of Group B (except LSG), they show similar fiber and pore diameters, and M layer porosity and thickness leading to similar hydraulic resistivity, water vapor transmission rate and surprisingly, to very high protection efficiencies for Group C SMS (above 96\%). The MPPS of the KC A20 and KC A30 fabrics, around $100 \mathrm{~nm}$, tend to prove that these differences in protection efficiency are due to a particle collection enhancement by electrostatic effects. ${ }^{[32]}$ This assumption is 
further reinforced by the manufacturer's technical specifications indicating a fiber treatment called "MICROFORCE®".

\section{Balance Between Protection and Comfort}

Thanks to the comfort-assessment measurements, it was possible to discuss the balance between protection and comfort. Indeed, this study showed that two SMS fabrics, namely $\mathrm{KC} \mathrm{A} 20$ and $\mathrm{KC} \mathrm{A30,} \mathrm{offered} \mathrm{all} \mathrm{the} \mathrm{comfort} \mathrm{advantages} \mathrm{of} \mathrm{SMS} \mathrm{materials,} \mathrm{i.e.,}$ low airflow resistance and high water vapor transmission rate, while achieving the same satisfactory level of protection efficiencies as the MP or FS fabrics. Nevertheless, it is crucial to note this supposed compromise only holds for protection against solid aerosols and may not remain valid for any other kind of chemicals (for instance, liquid aerosols and vapours). Moreover, even if very low fabric face velocities were used in this study, it is likely that the air velocities in actual work settings could sometimes be even lower. Thus, in some cases, it is possible, for example, that garments of Group B may reach higher efficiencies while still providing a good level of comfort. It is also worth pointing out that the fabric protection efficiency is only a part of that of the entire clothing. Indeed, other characteristics could have a major effect on protection efficiency, such as seams, skin/clothing interfaces and wear by abrasion or flexion. These aspects were part of the study and will be reported in a later article. Furthermore, movements of workers can be responsible for the so-called bellows effect which might create air convection, inward and outward of the protective clothing, altering both its protection and comfort. Thus, this quick assessment of compromise is essential, but it falls short of the multidimensional aspects of comfort. Further experimentations should be performed with human subjects at 
work wearing protective clothing made of different fabrics, to measure physiological strain, total inward leakage and a subjective assessment of comfort.

\section{CONCLUSIONS}

In general, for the three tested velocities, the results of the protection efficiency measurements highlighted the separation of the fabrics into three distinct groups (low, medium and very high protection efficiency). The low and medium efficiency groups are only composed of SMS (Spunbond/Meltblown/Spunbond). The very high efficiency group gathers all the microporous fabrics, the Tyvek $®$ (flashspun fabric) and two SMS. Most results could be explained by the characterization of the fabrics. Indeed, low, medium efficiency SMS and Tyvek® performances were found to be mostly due to the filtration layer thickness, i.e., the meltblown one and the whole fabric, respectively. As for microporous fabrics, submicronic pores provide efficiencies larger than 97\%. Finally, the approximately $100 \mathrm{~nm}$ MPPS and the manufacturer's datasheets of the two most protective SMS, highlighted a probable fiber electrostatic treatment explaining their performances. Combined with the comfort-assessment measurements, a compromise could be proposed that takes into consideration both comfort and protection. Indeed, these two very efficient SMS fabrics exhibit also a low level of airflow resistance and a high level of water vapor transmission rate. However, this compromise has certain caveats. It only holds for protection against solid aerosols and not against other kinds of chemicals (namely, liquid aerosols and vapour). 


\section{ACKNOWLEDGMENTS}

Grateful acknowledgment is extended to Dr. Geneviève Marchand, Carole-Anne Villeneuve and Joanna Augustin for their technical support regarding the fiber diameter measurements. We also thank Phil Gibson and Pearl Yip from the US Army Natick Soldier Research Development and Engineering Center for the measurements of the water vapor transmission rate.

\section{FUNDING}

This work was supported by the Institut de Recherche Robert-Sauvé en Santé et Sécurité du Travail (IRSST, Montréal, Canada).

\section{REFERENCES}

1. Boeniger, M. F.: The significance of skin exposure. Ann. Occup. Hyg., 47(8), 591-593 (2003).

2. National Institute for Occupational Health and Safety (NIOSH): Current intelligence bulletin 61: a strategy for assigning new NIOSH skin notations, 2009.

3. Sartorelli, P., H. W. Ahlers, K. Alanko, et al.: How to improve skin notation. Position paper from a workshop. Regul. Toxicol. Pharmacol., 49(3), 301-307 (2007).

4. Santos, R., and A. Goossens: An update on airborne contact dermatitis: 20012006. Contact Derm., 57(6), 353-360 (2007). 
5. Institut National de Recherche et Sécurité (INRS): Béryllium et composés minéraux: Généralités - Fiche toxicologique, 2017

6. Schloemer, J. A., M. J. Zirwas, and C. G. Burkhart: Airborne contact dermatitis: common causes in the USA. Int. J. Dermatol., 54(3), 271-274 (2015).

7. Crosera, M., M. Bovenzi, G. Maina, et al.: Nanoparticle dermal absorption and toxicity: a review of the literature. Int. Arch. Occup. Environ. Health, 82(9), 1043-1055 (2009).

8. Larese, F. F., F. D'Agostin, M. Crosera, et al.: Human skin penetration of silver nanoparticles through intact and damaged skin. Toxicology, 255(1), 33-37 (2009).

9. Larese, F. F., M. Crosera, M. Mauro, et al.: Palladium nanoparticles exposure: Evaluation of permeation through damaged and intact human skin. Environ. Pollut., 214(Supplement C), 497-503 (2016).

10. Larese, F. F., M. Mauro, G. Adami, M. Bovenzi, and M. Crosera: Nanoparticles skin absorption: New aspects for a safety profile evaluation. Regul. Toxicol. Pharmacol., 72(2), 310-322 (2015).

11. International Organization for Standardization (ISO): Vêtements de protection contre les produits chimiques -- Classification, étiquetage et exigences de performances (ISO 16602:2007). [Standard], 2007

12. International Organization for Standardization (ISO): Vêtements de protection à utiliser contre les particules solides -- Partie 1: Exigences de performance des vêtements de protection contre les produits chimiques offrant 
une protection au corps entier contre les particules solides transportées par l'air (vêtements de Type-5) (ISO 13982-1:2004). [Standard], 2004

13. International Organization for Standardization (ISO): Vêtements de protection à utiliser contre les particules solides -- Partie 2: Méthode d'essai pour la détermination de la fuite vers l'intérieur d'aérosols de fines particules dans des combinaisons (ISO 13982-2:2004). [Standard], 2004

14. Salah, M. B., S. Hallé, and L. Tuduri: Efficiency of five chemical protective clothing materials against nano and submicron aerosols when submitted to mechanical deformations. J. Occup. Environ. Hyg., 13(6), 425-433 (2016).

15. Vinches, L., and S. Hallé: Resistance of Type-5 chemical protective clothing against nanometric airborne particles: Behavior of seams and zipper. J. Occup. Environ. Hyg., 14(12), 939-946 (2017).

16. Golanski, L., A. Guiot, F. Rouillon, J. Pocachard, and F. Tardif: Experimental evaluation of personal protection devices against graphite nanoaerosols: fibrous filter media, masks, protective clothing, and gloves. Hum. Exp. Toxicol., 28(6-7), 353-359 (2009).

17. Gao, P., P. A. Jaques, T. Hsiao, et al.: Evaluation of Nano- and Submicron Particle Penetration through Ten Nonwoven Fabrics Using a Wind-Driven Approach. J. Occup. Environ. Hyg., 8(1), 13-22 (2011).

18. Golanski, L., A. Guiot, and F. Tardif: Experimental evaluation of individual protection devices against different types of nanoaerosols: graphite, TiO2, and Pt. J. Nanoparticle Res., 12(1), 83-89 (2010). 
19. Hinds, W. C.: Aerosol technology properties, behavior, and measurement of airborne particles. New York: Wiley, 1999.

20. American Society of Heating, Refrigerating and Air-Conditioning Engineers (ASHRAE): Method of testing general ventilation air cleaning devices for removal efficiency by particle size (ASHRAE 52.2-2012). [Standard], 2012

21. Brasser, P.: Theoretical and experimental study of airflow through clothing around body parts. AIChE J., 52(11), 3688-3695 (2006).

22. Baldwin, P. E., and A. D. Maynard: A survey of wind speeds in indoor workplaces. Ann. Occup. Hyg., 42(5), 303-313 (1998).

23. European Committee for Standardization: European test method for air filters (EN 779:2012). [Standard], 2012

24. American Society for Testing and Material (ASTM): Test Methods for Water Vapor Diffusion Resistance and Air Flow Resistance of Clothing Materials Using the Dynamic Moisture Permeation Cell (ASTM F2298). [Standard], 2009 (withdrawn).

25. Standards Council of Canada: Textile Test Methods: Fabric Thickness (CAN/CGSB-4.2 No. 37-2002 (R2013)). [Standard], 2013

26. Standards Council of Canada: Textile Test Methods : Unit Mass of Fabrics (CAN/CGSB-4.2 No./N 5.1-M90 (R2013) ). [Standard], 2013

27. American Society for Testing and Material (ASTM): Test Methods for Density and Specific Gravity (Relative Density) of Plastics by Displacement (ASTM D792). [Standard], 2008 
28. Davies, C. N.: Air filtration. London New York : Academic Press, 1973.

29. American Society for Testing and Material (ASTM): Test Method for Pore Size Characteristics of Geotextiles by Capillary Flow Test (ASTM D6767). [Standard], 2016

30. Hutten, I. M.: Handbook of Nonwoven Filter Media. Butterworth-Heinemann, 2015.

31. McCormack, A. L., and W. B. Haffner: Microporous elastomeric film/nonwoven breathable laminate and method for making the same, US Patent 6,015,764 A, filed Jan. 18, 2000.

32. Tang, M., S. Chen, D. Chang et al.: Filtration efficiency and loading characteristics of PM2.5 through composite filter media consisting of commercial HVAC electret media and nanofiber layer. Sep. Purif. Technol., 198, 137-145 (2018). 